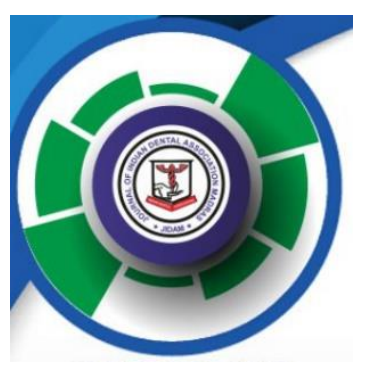

CASE REPORT

\title{
REIMPLANTATION: BOON TO DENTISTRY - A CASE REPORT
}

\author{
Dr. V. Balakumar, Dr. R. Haribabu, Dr. K. Vidya BDS, Dr. R. Bhavani*
}

Department of Prosthodontics, Sathyabama Dental College and Hospital, Jeppiar Nagar, Chennai, Tamilnadu, India

*Consultant, V.B.K Dental Foundations, Chennai, Tamilnadu, India

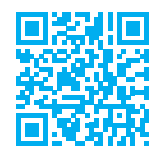

DOI:10.37841/jidam_2021_V8_I1_07

Address for Correspondence:

Dr. V. Balakumar., MDS.,

Professor, Department of Prosthodontics,

Sathyabama Dental College, Jeppiar Nagar,

Chennai-600119, Tamilnadu, India

Email id: venkatbala_123@yahoo.com

\section{ABSTRACT}

Avulsion of permanent teeth is the most common dental injuries in a road traffic accident. It's a boon that the patient's original teeth can be replanted provided the fracture of the tooth and socket are within limits. Educating the community plays a major role in reimplantation. In this case report, the patient's avulsed maxillary central incisors $(11,21)$ were replanted by simple composite splinting technique.

KEY WORDS: Avulsed tooth, Composite splinting, Reimplantation, Golden hour.

Received: 4.11.2020 First Published: 27.02.2021

Accepted: 14.02.2021 Published: 27.03.2021 
Balakumar et al: Reimplantation- A case report

\section{INTRODUCTION}

Teeth are an integral part of stomatognathic system with their functions - smiling, phonetics and mastication. An attractive smile is the important social asset and makes someone more appealing. Smile can convey confidence and an appearance, which simply reflects our emotional expression.

Loosing teeth at young age could be of various reasons ranging from trauma to gum diseases, which has physiological traits including self-esteem, optimism, depression, stress about appearance. When there is an option of replanting our own teeth, it will boost self-confidence and satisfaction. $^{2}$ The procedure is known as reimplantation which is a boon to dentistry.

Reimplantation refers to the insertion and fixation of completely or partly avulsed teeth that have been resulted from traumatic injury. ${ }^{13}$ The most conservative approach for managing the avulsed incisors is to replant them as soon as possible.

Dental avulsion is a type of dental trauma and its prevalence is estimated as $17.5 \%$. Males are affected 3 times more than females. Prevalence is more among school children and sports person. ${ }^{14}$

\section{CASE REPORT}

A 17 year old male patient reported to the hospital with bleeding per mouth. The history revealed that the patient had met with an road traffic accident 10 minutes ago. On examination, found that the upper central incisors $(11,21)$ were missing.

The patient elaborated that accident took place 10 minutes ago and both his upper anterior teeth were avulsed as a whole, but was dropped at the accident site. Patient's kin $^{5}$ was advised to bring back the avulsed teeth from the accident site by holding the crown part ${ }^{10}$ of the teeth and transporting them in a bowl of milk (Figure 3). ${ }^{2,7}$ IOPA X ray (Figure 1) was taken to confirm that the teeth were avulsed as a whole and also to evaluate the socket . Debridement of the avulsed socket was done in an aseptic way with hank's balanced salt solution ${ }^{9}$ (Figure 2) and povidone iodine ${ }^{8}$, to remove blood clot and thereby creating fresh bleeding of the socket.

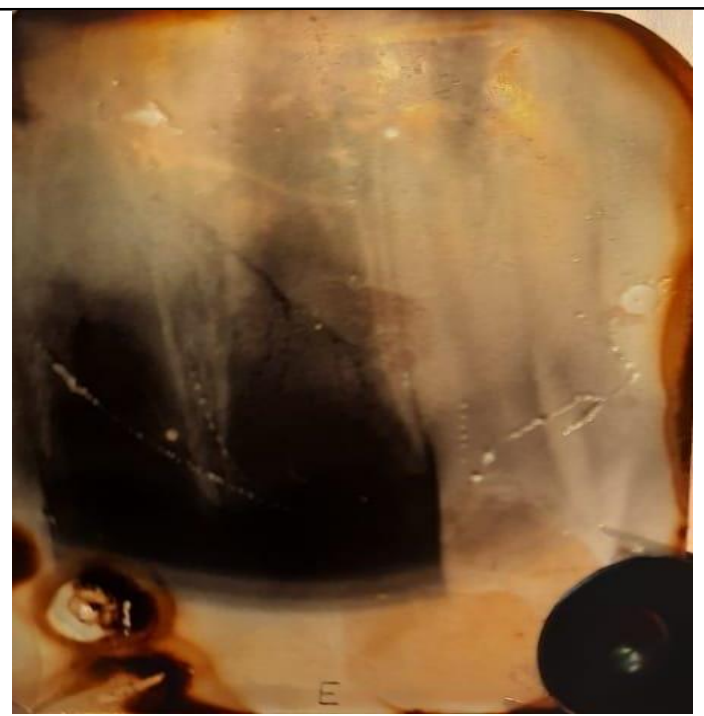

Figure 1: IOPA reveals completely avulsed 1121 and no fracture of bone

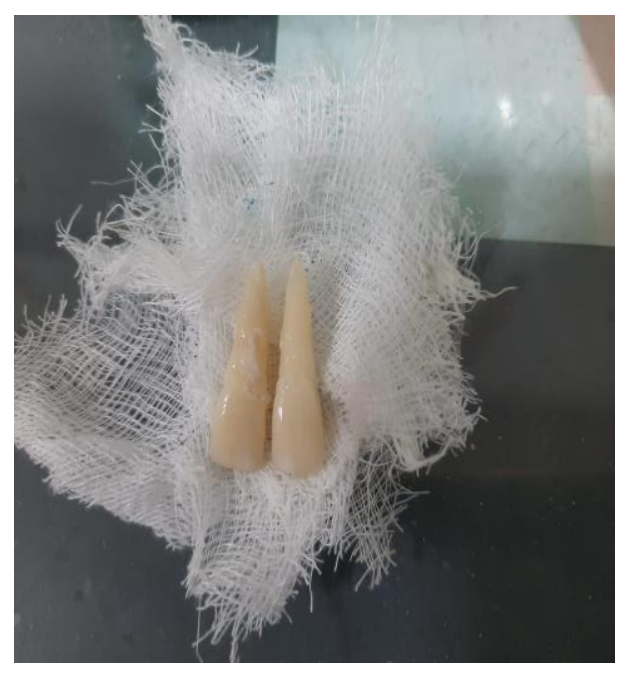

Figure 2: Avulsed 11,21

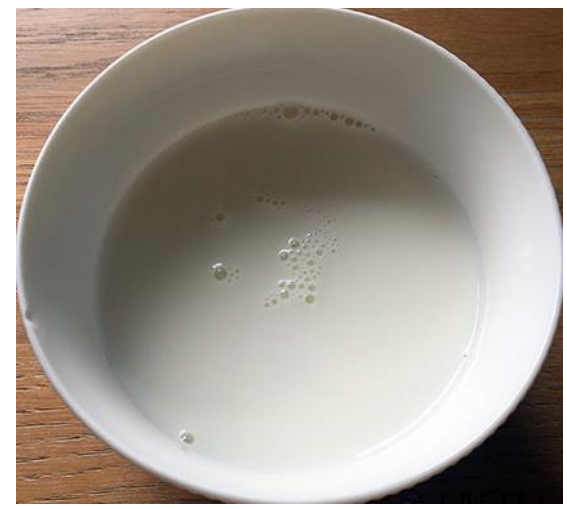

Figure 3: Bowl of milk as medium of transport 
The avulsed teeth were brought back within minutes and thorough debridement was done(Figure 4 ) by holding the crown part of the tooth with running saline. ${ }^{9}$ After which the tooth was inserted in their respective socket to check for initial stability. The teeth was held in position by asking the patient to bite on a sterile gauze ${ }^{10}$ (Figure 5) and digital palpitation was conducted on both labial and palatal surface to check the cortical plates were intact. Patient was asked to occlude in centric occlusion to check any pre matured contacts, selective grinding to be done if required.

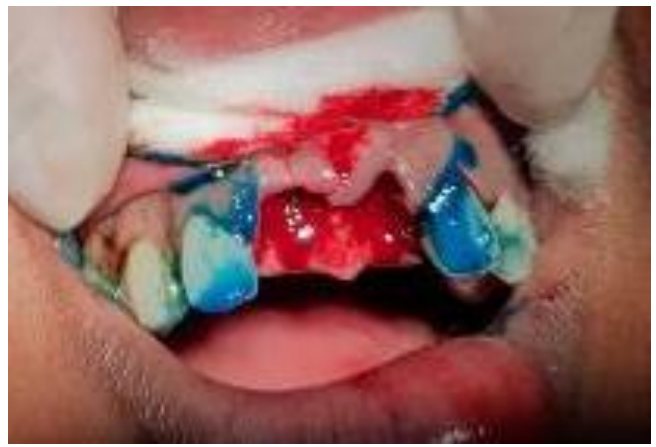

Figure 4: Debridement of the avulsed socket along with acid etching

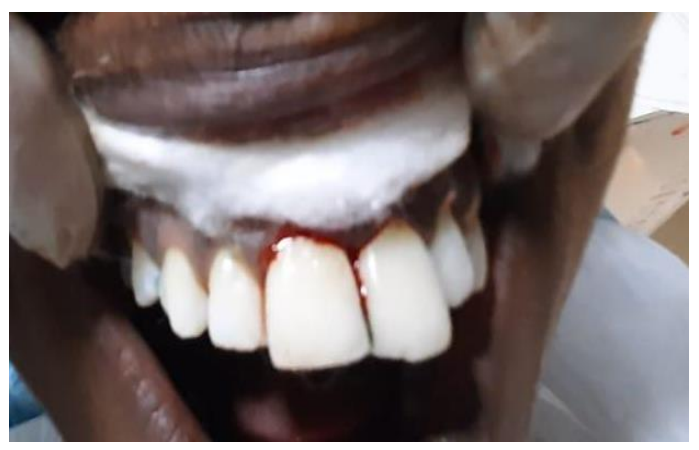

Figure 5: Avulsed 11,21 placed in their respective sockets to check snug fit

Stabilization splinting was done using a stainless steel wire with Ivoclar composite resin extending from canine to canine $^{1,12}$ (Figure 6) Centric, eccentric premature contacts are checked with articulating paper and interferences relieved. Oral hygiene instructions were given and the patient was periodically reviewed.

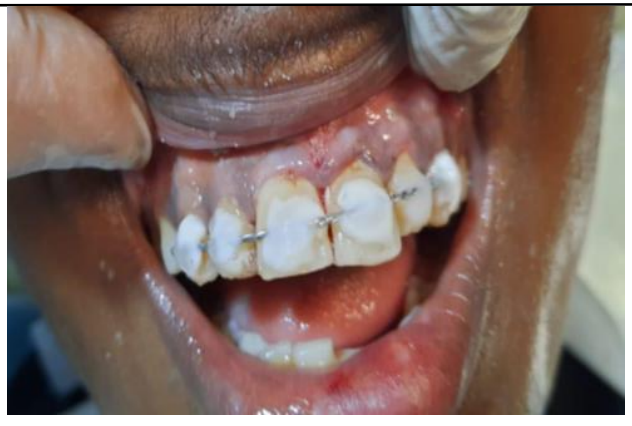

Figure 6: Composite splitting done and stabilized

\section{DISCUSSION}

Reimplantation is a unique treatment of choice for avulsion of tooth. Prognosis is always positive for completely avulsed tooth. Hence in this case the teeth was avulsed as a whole thereby reimplantation was attempted.

Success of an avulsed tooth is higher if replanted within 15-20 minutes. This time period is known as golden hour. ${ }^{15}$ Reimplantation was planned for this particular case because the dry time was within the golden hour. The advantages of replanting the tooth within this golden hour are preservation of periodontal ligament vitality and reattachment, minimal inflammatory responses, repair with replacement of cementum. Disadvantages would be ankylosis, replacement resorption and external inflammatory root resorption. ${ }^{15}$

The available medium of transportation for avulsed tooth are water, hank's balanced salt solution, milk $^{2,7}$, coconut water ${ }^{3}$ and patient saliva. ${ }^{3}$ Milk is a better choice of medium $^{2}$, since high percentage of vital cells maintained for six hours and easy availability reason ${ }^{2,7}$. Therefore the avulsed teeth were transported in a bowl of milk from the accident site.

Holding the tooth in the root portion would lead to disembarkment of the periodontal ligaments. Hence it is always important to handle the avulsed tooth by handling the crown portion of the tooth. ${ }^{10}$ Same was instructed to the patient's kin. ${ }^{5,10}$

A through debridement of socket is a must with water and saline to remove blood clot and thereby creating fresh bleeding of the socket for better prognosis. It is mandatory to check the anatomical position of the teeth in the socket to establish initial stabilization. Splinting is a method of stabilization of avulsed tooth by using composite resin ${ }^{1.10}$, as it is the material of choice for esthetics. 
Balakumar et al: Reimplantation- A case report

\section{CONCLUSION}

Reimplantation of avulsed permanent tooth is a boon to dentistry. The prognosis of reimplantation depends upon the extent of trauma, minimizing the extra oral dry time, material of choice of splinting, duration of stabilization and occlusal factors. Composite splitting is the traditional method of stabilization from past to present. Reimplantation of one's natural tooth with utmost care will build up selfconfidence and psychological wellbeing.

\section{FINANCIAL SUPPORT AND SPONSORSHIP}

Nil

\section{CONFLICTS OF INTEREST}

There are no conflicts of interest.

\section{REFERENCES}

1. Management of Dento alveolar fracture by using rigid wire and composite splint : A case report Multidisciplinary journal of science and medical research(MJSM) . June 2018 DOI 10.15562 volume 9 issue 2 page 266.

2. L.Blomlof, L.Andersson Storage of experimentally avulsed teeth in milk prior to reimplantion. Research article Pub med August $1^{\text {st }} 1983$.

3. V.Gopikrishna, Toby Thomas, Dr.Kandasamy A quantitative analysis of coconut water : A new storage media for avulsed teeth. Oral Surgery, Oral Mendicine, Oral Pathologoly, Oral Radiol and Endodontol Volume 105 : Issue 2 Febuary 2008 pg 61- 65 .

4. Esinozlek Burak AL. A five year follow up of delayed reimplanted avulsed tooth - A case report. Eastern journal of Medicine(EJM) Volume 23 Issue 42018 pg $350-354$.

5. Parents and care takers knowledge about avulsion of permanent teeth. Dental Traumatology(DT) March 2009 Volume 25 Issue 2 Page 203-208

6. Lars Andresson, Genos $\mathrm{O}$ Andreasen International association of dental traumatogoly guidelines of management of traumatic dental injuries to avulsion of permanent teeth. Dental Traumatology(DT) Volume 28 : Issue 2: April 2012 Page 88 - 96.

7. E Orest M Harkacz, David L Carnes et al .Determination of PDL cells viability in the oral rehydration fluid. Gatoracle and milk of various fat content. Journal of Endodontics (JOE) Volume 23: Issue11: November 1997 Pg 687-690.
8. The efficiency and risk of using povidone iodine irrigation to prevent surgical site infection. An evidence based review. Canadian journal of Surgery(CJS) December 2007 Volume 50 Issue 8 PG 473- 481.

9. Nathalia Carolina Fernandes , Fagundes 1,2, Leonardo Oliveira Bittencourt1, Marcela Barau'na Magno3 PLOS ONE .Efficacy of Hank's balanced salt solution compared to other solutions in the preservation of the periodontal ligament. A systematic review and meta-analysis. July 13, 2018. Page 1- 19

10. Ashraf. F.Fouad, Paul Abbort et al International Association of Dental Traumatology guidelines for the management of traumatic dental injuries: 2 . Avulsion of permanent teeth. Dental taumatology volume 36 issue 4 page 331 - 342

11. Krishnapriya, suhasNe Ne, Vikas Bendgude. Prognosis of replanted avulsed permanent incisors : a systematic review. 2018 volume 3 , issue 2 , page no 87-98.

12. B.Kahler, J.Y.Hu, C.S.Marriot Smith .Splinting of teeth following trauma : a review and a new splinting recommendation. An Australian dental journal . march 2016, volume 61, issue S1, page no 59-73.

13. Reimplantation : Clinical implication and outcome of dry storage of avulsed teeth. Journal of clinical and experimental dentistry . february 2010, volume 2 , issue 1 , page no 37-41.

14. Dental avulsion - wikipedia .

15. Lieutenant Sherma Saif, Commander Patricia, A Tordik. Clinical update . avulsed permanent teeth a new treatment guideline. February 2004 , volume 26 , issue 2 , page no 28-31. 